\title{
The Social Meaning of the Age at Second Birth for Third-Birth Fertility: A Methodological Note on the Need to Sometimes Respecify an Intermediate Variable
}

\author{
BRITTA HOEM \\ Program Director \\ Statistics Sweden \\ Stockholm, Sweden
}

\begin{abstract}
In hazard regressions for a number of countries, including Sweden, more highly educated women have been found to have higher third-birth rates than other women. In this paper we show that this positive educational gradient disappears when age at second birth is respecified in order to better catch what age at second birth means to women at the various levels of education. Instead of a conventional age grouping that is the same for all educational categories, we suggest that the age factor should be defined so as to reflect what is normal and unusual childbearing behavior for each educational level separately. Considerations of a similar nature can be equally important in other contexts.
\end{abstract}

Keywords: women, education, age, second birth, third birth, regression analysis, Sweden

\section{Introduction}

Intensity regression is now commonly used to study the effect of one variable on demographic behavior while the level of other covariates is kept under control by means of the regression specification. For instance, intensity-regression models are used to analyze the effect of education on the rate at which women at parity 2 get a third child, controlling for age at second birth and other variables. In such an analysis, it is important to account for the very different distributions of age at second birth that women have at different educational levels, otherwise incorrect conclusions may be drawn from the analysis.

In a hazard-regression analysis of parity progression among Swedish women at parities 1 and 2 (Hoem and Hoem, 1989), we discovered that among Swedish women in the 1960 s and 1970 s, the more highly educated had the higher birth rates at most durations since the birth of the youngest child when we controlled for age at last previous birth, the interval between the first two births, and a number of other covariates. Similar findings have been made later for Norway and the United States (Kravdal, 1992), for West-Germany (Huinink, 1988, 1989), and for Britain (Ní Bhrolcháin, 1993). ${ }^{1}$

1 Wright et al. (1988) found no effect of educational level on third-birth rates for Britain. In a 
We reproduce them again for more recent Swedish data below. In such investigations, including our own, starting age has been grouped in the same manner for women at all educational levels. This is common practice, and it may be motivated by the idea that such a procedure should bring out the marginal effect of the educational level (on the childbearing hazard), net of any compositional effect of starting age and other covariates included in the hazard regression.

In the present note we challenge that notion and suggest that it would be better to group the age variable differently for women at different educational levels in order to reflect normal and unusual ages at childbearing in each educational group taken separately. We suggest that the effect of a given covariate on behavior such as childbearing must depend on its social meaning among a person's peers and not on its average meaning in the population as a whole. An age at second birth that is normal in one educational group, may be quite unusual in another group. An extreme value of such an age covariate may be a predictor of behavior that is unusual for members of the relevant educational or social group at later stages in life as well. If what is regarded as extreme varies between social groups, then the intermediate covariate should be specified in a manner that reflects rather than disregards this fact.

To pursue these ideas we have specified an age variable whose grouping is relative to each educational level in an extensive set of register data for Swedish women that we have at our disposal. For women at parity 2, we have defined the age at second birth as 'very young', 'rather young', 'medium', 'rather old', and 'oldest' for the woman's educational level, in a manner which takes ages below 23 to be 'very young' and ages above 30 to be 'oldest' for women with less than a gymnasium $^{2}$ education, while a woman with a university-level education is recorded in those categories if she has her second birth at ages below 28 and above 35 instead, respectively. With this definition of the age variable, the positive gradient in the effect of educational level on the third-birth hazard disappears.

\section{Data, method, and first results}

The data used for this study have been extracted from registers kept by Statistics Sweden. We have used data on births recorded for all women who were Swedish citizens and resident in Sweden as of the Census of 1960, or who are daughters of such women, and who were born in 1939 through 1964. For each such woman, her highest education ever recorded by 1990 has been added. ${ }^{3}$ After the elimination of some incomplete records and of records for women who had twins in their first or second live confinements, we have at our disposal information on about 814,000 women who had recorded first and second live single births and for whom we know the educational level by 1990 . We have run proportional-hazard regressions for the third-birth "risk" of such women with the covariates whose main effects are indicated in Column 2 of Table 1 and with months since the second birth as our time vari-

response to an earlier version of the present paper, Toulemon (1995) found a U-shaped educational effect for France.

${ }^{2}$ Education below the gymnasium is compulsory in Sweden. Young people normally enter the gymnasium at age 16 and leave it at age 19. Completed gymnasium qualifications are a minimum prerequisite for entry into a university-level education.

${ }^{3}$ For a proper understanding of the influence of educational level on the third-birth intensity it would have been better to know the education at second birth, but that is beside the point here. Our purpose is not primarily to display the educational effect but to highlight the change in this effect that is produced by a redefinition of the age at second birth. 
T a b l e 1. Effects of some covariates on third-birth hazards for Swedish cohorts born in 1939-64

Relative risk with age at second birth defined in terms of

$\begin{array}{cc}\text { Factor } & \begin{array}{c}\text { Number of } \\ \text { records }\end{array} \\ \end{array}$

(1)

Year of birth

87350
112289
120707
111851
100141
93939
84856
65463
37805

$\underline{\text { Age at second birth }}^{\mathrm{a}}$

very young

rather young

medium

rather old

oldest

\section{Months between first two births}

-17 months

$18-29 "$

20-41»

42-59 »

$60+»$

Educational level

below gymnasium

gymn. $<3$ yrs.

gymn. > 3 yrs.

brief post-gymn. ${ }^{\text {b }}$

long post-gymn. ${ }^{\mathrm{C}}$

50898
224901
219905
169948
148749

205792

333094

64997

118240

90778
(2)

$\begin{array}{ll}1.19 & 1.19 \\ 1.04 & 1.05 \\ 1 & 1 \\ 1.09 & 1.09 \\ 1.23 & 1.23 \\ 1.46 & 1.46 \\ 1.70 & 1.69 \\ 1.80 & 1.78 \\ 1.78 & 1.75\end{array}$

(3)

(1)

23

.69

1.75

NOTES:

a The covariate 'age at second birth' is defined as follows in Column 2. (See Table 4 for its definition in Column 3.)

$\begin{array}{ll}1.35 & 1.23 \\ 1 & 1 \\ 0.79 & 0.79 \\ 0.61 & 0.61 \\ 0.38 & 0.42\end{array}$

relative to

educational level $^{a}$

C.

0.79

0.42

$1.29 \quad 1.29$

$0.71 \quad 0.71$

$\begin{array}{ll}0.56 & 0.57\end{array}$

$\begin{array}{ll}0.66 & 0.67\end{array}$

$1.08-1.15$

$1 \quad 1$

$\begin{array}{ll}0.96 & 0.89\end{array}$

$\begin{array}{ll}1.15 & 1.00\end{array}$

$\begin{array}{ll}1.40 & 1.12\end{array}$

.15
.89
1.00

$\begin{array}{lcr} & & \text { Number of re } \\ \text { very young } & -23 \text { yrs } & 179085 \\ \text { rather young } & 24-26 » & 211115 \\ \text { medium } & 27-29 » & 212178 \\ \text { rather old } & 30-34 » & 171482 \\ \text { oldest } & 35+» & 40541\end{array}$

${ }^{\mathrm{b}}$ Less than three years of post-gymnasium education.

c Three years or more of post-gymnasium education, but less than a doctoral degree. 
able. ${ }^{4}$ The very large number of records at our disposal permits us to use an unusually fine specification of the levels of the covariates we use. We have also included some interactions and report the outcome of one such run below.

The effects reported in Table 1 are relative risks and should be understood as follows. For the cohort covariate, we have chosen women born in 1945-47 as our baseline group, indicated by the figure 1 (without decimals) in Column 2 . The relative risk for the cohort of 1960-62 is estimated at 1.80 , which means that (at parity 2) women in the latter cohort have estimated 80 percent higher third-birth rates than women in the baseline cohort do when we control for the other covariates included in the regression. Evidently, third-birth fertility has risen considerably over the Swedish cohorts born after World War II, fully in line with observed period effects (Hoem, 1993).

The effects of the other covariates have similar interpretations. We see that as usual there is a negative gradient in the effect of a woman's age at second birth and in the effect of the interval between her first two births.

The effect of a woman's educational level is more problematic and we discuss it in our next Section.

$\mathrm{T} \mathrm{a} \mathrm{b} \mathrm{le} \mathrm{2.} \mathrm{Distribution} \mathrm{of} \mathrm{respondents} \mathrm{by} \mathrm{educational} \mathrm{level} \mathrm{and} \mathrm{age} \mathrm{at} \mathrm{second} \mathrm{birth}$

\begin{tabular}{|c|c|c|c|c|c|}
\hline \multirow{3}{*}{ Educational level } & \multicolumn{5}{|c|}{$\begin{array}{l}\text { A. Absolute numbers } \\
\text { Age at second birth }\end{array}$} \\
\hline & -23 & $24-26$ & $27-29$ & $30-34$ & $35+$ \\
\hline & & & & & \\
\hline below gymnasium & 74569 & 57747 & 40454 & 26785 & 6237 \\
\hline ymn. $<3$ yrs. & 81077 & 99506 & 85272 & 56099 & 11140 \\
\hline$y m n .>=3 \mathrm{yrs}$ & 8374 & 16536 & 20302 & 16226 & 3559 \\
\hline brief post-gymn. & 10676 & 24505 & 38741 & 36461 & 8157 \\
\hline long post-gymn. & 4353 & 12977 & 27057 & 35378 & 11113 \\
\hline & \multicolumn{5}{|c|}{ B. Percent for each educational level } \\
\hline & \multicolumn{5}{|c|}{ Age at second birth } \\
\hline & -23 & $24-26$ & $27-29$ & $30-34$ & $35+$ \\
\hline \multicolumn{6}{|l|}{ Educational level } \\
\hline low gymnasium & 36.2 & 28.1 & 19.7 & 13.0 & 3.0 \\
\hline$m n .<3$ yrs. & 24.3 & 29.9 & 25.6 & 16.8 & 3.3 \\
\hline$m n .>=3 \mathrm{yrs}$ & 12.9 & 25.4 & 31.2 & 25.0 & 5.5 \\
\hline ief post-gymn. & 9.0 & 20.5 & 32.8 & 30.8 & 6.9 \\
\hline ng post-gymn. & 4.8 & 14.3 & 29.8 & 38.9 & 12.2 \\
\hline
\end{tabular}

\section{Educational level and age at second birth}

In the model of Column 2 in Table 1, there is a positive gradient in the educational effect, well in line with what has been found in previous investigations. Table 2 shows, however, that at the various educational levels women are distributed quite differently over the fixed age groups used in that regression. While over one third of the women with less than a gymnasium education have their second births before age 24 ,

${ }^{4}$ The effect of the time variable has little interest for our present concerns and is not reported here. A respecification in terms of age at first birth and the subsequent birth interval gave no new insight into the issues raised here. We will return to Column 3 below. 
$\mathrm{T} \mathrm{a} \mathrm{b} \mathrm{le} \mathrm{3.} \mathrm{Interaction} \mathrm{between} \mathrm{educational} \mathrm{level} \mathrm{and} \mathrm{age} \mathrm{at} \mathrm{second} \mathrm{birth} \mathrm{in} \mathrm{our} \mathrm{third-}$ birth hazard regression for Swedish cohorts born in 1939-64

\begin{tabular}{|c|c|c|c|c|c|}
\hline & & & t seconc & & \\
\hline & -23 & $24-26$ & $27-29$ & $30-34$ & $35+$ \\
\hline $\begin{array}{l}\text { Educational level } \\
\text { below gymnasium }\end{array}$ & 1.48 & 1 & 0.71 & 0.49 & \\
\hline gymn. $<3$ yrs. & 1.29 & 0.97 & 0.72 & 0.54 & \\
\hline gymn. $>=3$ yrs. & 1.16 & 0.93 & 0.72 & 0.57 & 0 . \\
\hline brief post-gymn. & 1.09 & 1.07 & 0.95 & 0.74 & 0.48 \\
\hline long post-gymn. & 1.17 & 1.28 & 1.12 & 0.86 & 0.50 \\
\hline
\end{tabular}

only about five per cent of women with a long post-gymnasium education (mostly to achieve a university degree on the bachelor level, or its equivalent) have their second births that early. It is evident that such an age at second birth has a completely different social meaning for university graduates than for those with only compulsory education. What is completely normal childbearing behavior for one educational group is quite unusual in another. This in itself may have produced the positive educational gradient that has been found in previous studies and that is visible again in Column 2 in our Table 1.

A standard way of illuminating the joint effect of age at second birth and educational level is to include their interaction in the hazard regression, as in Table $3 .{ }^{5}$ We now see from the first column of the table that there is a largely negative educational gradient in the third-birth hazard for women who had their second birth before age 24 . In the other age groups, the educational gradients remain positive. ${ }^{6}$ The interac-

T a b l e 4. Respecification of the covariate 'age at second birth'

A. New age intervals specific for educational level

\begin{tabular}{|c|c|c|c|c|c|}
\hline & $\begin{array}{l}\text { very } \\
\text { young }\end{array}$ & $\begin{array}{l}\text { rather } \\
\text { young }\end{array}$ & medium & $\begin{array}{c}\text { rather } \\
\text { old }\end{array}$ & oldest \\
\hline \multicolumn{6}{|l|}{ Educational level } \\
\hline below gymnasium & -22 & $23-24$ & $25-27$ & $28-30$ & $31+$ \\
\hline gymn. < 3 yrs. & -23 & $24-25$ & $26-28$ & $29-31$ & $32+$ \\
\hline gymn. $>=3$ yrs. & -24 & $25-26$ & $27-29$ & $30-32$ & $33+$ \\
\hline brief post-gymn. & -25 & $26-27$ & $28-30$ & $31-33$ & $34+$ \\
\hline long post-gymn. & -26 & $27-28$ & $29-31$ & $32-34$ & $35+$ \\
\hline
\end{tabular}

B. Percent for each educational level

Age at second birth

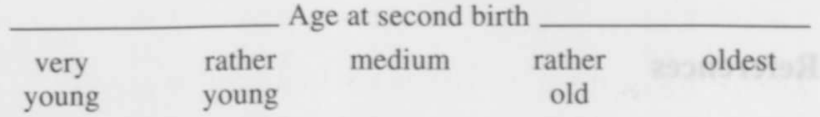

Educational level

\begin{tabular}{llllll}
\hline below gymnasium & 26.5 & 19.7 & 26.0 & 16.0 & 11.9 \\
gymn.$<3$ yrs. & 24.3 & 19.6 & 28.8 & 16.8 & 10.4 \\
gymn. $>=3$ yrs. & 19.7 & 18.7 & 31.2 & 18.8 & 11.6 \\
brief post-gymn. & 20.6 & 19.9 & 31.1 & 18.2 & 10.2 \\
long post-gymn. & 19.1 & 19.1 & 30.4 & 19.2 & 12.2
\end{tabular}

${ }^{5}$ The effects of other covariates is hardly affected by this specification and are not displayed again here.

${ }^{6}$ The main effects in Column 2 of Table 2 are dominated by the latter groups. 
tion table suffers from the same defect as the corresponding main effects did, however. Inclusion of the interaction does not compensate for the differential distribution of respondents at different educational levels over age groups at second birth. If, in an attempt at catching modal childbearing behavior, for instance, we list the interaction coefficients of the most common age group for each educational level, ${ }^{7}$ the educational gradient is no longer positive.

To get a firmer grip on the age variable, we respecify it as indicated in the upper panel of Table 4 . The new age grouping for the educational levels is a practical compromise between (i) an aspiration to split the records into five roughly equally large segments at each educational level, (ii) the need to stick to integer-age groups, and (iii) a secondary wish for simplicity. With this new age variable, the effect of educational level changes drastically (Column 3 in Table 1). While the impacts of other covariates, including that of the age variable itself, are hardly affected by the respecification, there is no longer any noticeable gradient in the educational effects. This suggests that women's educational level influences the age pattern of second births but that it is unimportant for the extent to which women of parity 2 have third births at each duration, net of the covariates included here.

\section{Discussion}

We have carried out this analysis because we have a particular interest in better understanding how education influences fertility, but we are convinced that it must be important to use a similar procedure whenever the impact of a less proximate variable (such as educational level) on some behavior (such as third birth) is strongly influenced by an intermediary variable (here age at second birth) and the respondents have a distribution over the levels of the intermediary variable that varies strongly between categories on the less proximate variable. Then the intermediary variable should be respecified into categories that depend on the level of the less proximate variable in a manner that makes its new categories meaningfully comparable across the levels of the latter instead of fixed, as is now common practice.

\section{Acknowledgement}

The author is grateful to Jan M. Hoem for discussions concerning the content and presentation of this material.

\section{References}

Hoem, Britta.1993. The compatibility of employment and childbearing in contemporary Sweden. Acta Sociologica 36:101-120.

Hoem, Britta and Jan M. Hoem. 1989. The impact of women's employment on second and third births in modern Sweden. Population Studies 43(1): 47-67.

7 The sequence of coefficients becomes $1.48,0.97,0.72,0.95$, and 0.86 for women with less than a gymnasium education, women with a brief gymnasium education, and so on, respectively. We used a procedure of this nature when we pointed out the issues addressed here in an earlier paper (B. Hoem, 1993). 
Hoem, Jan M. 1993. Classical demographic methods of analysis and modern event-history techniques. In: International Population Conference, 24 August-1st September, 1993, Montreal, pp. 281-291. Liège: IUSSP.

Huinink, Johannes. 1988. Das zweite und dritte Kind: Sind wir auf dem Weg zur Ein-Kind-Familie? Universität Mannheim, Sonderforschungsbereich 3, Arbeitspapier Nr. 272.

Huinink, Johannes. 1989. Das zweite Kind: Sind wir auf dem Weg zur Ein-Kind-Familie? Zeitschrift für Sociologie 18(3): 192-207.

Kravdal, Øystein.1992. The emergence of a positive relation between education and third birth rates in Norway with supporting evidence from the United States. Population Studies 46(3):459-475.

Ní Bhrolcháin, Máire. 1993. Recent fertility differentials in Britain. In: New Perspectives on Fertility in Britain, edited by Máire Ní Brolcháin, pp. 93-109. Studies on Medical and Population Subjects, No. 55. London: HMSO.

Toulemon, Laurent.1995. Analyse des biographies et compairaison entre groupes: niveau de diplôme et arrivée du troisième enfant en France. Paper for the EAPS/IUSSP European Population Conference, Milan, September 1995.

Wright, R.E., J.F. Ermisch, P.R.A. Hinde, and H. Joshi. 1988. The third birth in Great Britain. Journal of Biosocial Science. 20(4):489-496. 